\title{
Perception of quality and complexity in wine and their links to varietal typicality: An investigation involving Pinot noir wine and professional tasters
}

\author{
Wendy V. Parr ${ }^{\mathrm{a}, *}$, Claire Grose ${ }^{\mathrm{b}}$, Duncan Hedderley ${ }^{\mathrm{c}}$, Marcela Medel Maraboli ${ }^{\mathrm{d}}$, Oliver Masters ${ }^{\mathrm{e}}$, \\ Leandro Dias Araujo ${ }^{\mathrm{f}}$, Dominique Valentin ${ }^{g}$
}

${ }^{a}$ AGLS Faculty, Lincoln University, Christchurch, New Zealand

${ }^{\mathrm{b}}$ Institute of Plant and Food Research, Marlborough, New Zealand

${ }^{\mathrm{c}}$ Institute of Plant and Food Research, Palmerston North, New Zealand

${ }^{\mathrm{d}}$ University of Chile, Santiago, Chile

e Tripwire Wine Consulting Ltd. \& Misha's Vineyard, Central Otago, New Zealand

${ }^{\mathrm{f}}$ School of Chemical Sciences, The University of Auckland, New Zealand

${ }^{g}$ CSGA UMR5170 CNRS, University of Burgundy, INRA, France

A R T I C L E IN F O

\section{Keywords:}

Pinot noir

Quality

Complexity

Varietal typicality

Sensory

Colour

\begin{abstract}
A B S T R A C T
Quality and complexity are abstract terms employed frequently to describe a wine's overall attributes. In the present study, we investigated: (i) attributes driving wine professionals' judgments of quality and complexity in Pinot noir wines; (ii) the relation between these two abstract concepts; and (iii) association of each concept with varietal typicality. Twenty-two wine professionals evaluated 18 New Zealand Pinot noir wines in both clear and opaque glassware via two sensory tasks, a descriptive rating task and an 8-attribute, perceived complexity questionnaire. Sensory data were associated with wine UV-spectrophotometry colour measures to aid interpretation of the influence of tasting-glass colour. Results demonstrated the key drivers of perceived quality were descriptors varietal typicality, expressiveness, overall structure, and attractive fruit aromatics, along with complexity questionnaire attributes of harmony, balance and number of identifiable flavours. Reductive notes drove low-quality judgments. Data show that quality and complexity were positively associated concepts and that both were linked positively with varietal typicality. Visual influence was not a major driver of wine professionals' judgments but being able to see a wine's colour influenced tasters' judgments to wines at each end of the price/quality spectrum. We discuss the results in terms of cognitive phenomena associated with judgments by those with domain-specific expertise.
\end{abstract}

\section{Introduction}

Recent decades have seen increased scientific scrutiny of terms used frequently by wine critics to refer to the abstract qualities of wine. Investigations of perceived quality (Charters \& Pettigrew, 2007; Hopfer \& Heymann, 2014; Valentin, Parr, Peyron, Grose, \& Ballester, 2016) and complexity (Schlich, Medel, Urbano, \& Parr, 2015; Wang \& Spence, 2018) have demonstrated that both wine professionals and wine consumers consider these concepts to be positive aspects of a wine. Studies of other abstract qualities such as minerality and typicality, arguably less significant or meaningful to wine consumers, have generally been limited to tasters deemed to have domain-specific expertise. These studies have demonstrated that perceived minerality (Parr, Ballester, Peyron, Grose, \& Valentin, 2015; Rodrigues et al., 2017) and perceived typicality (Ballester, Dacremont, Le Fur, \& Etievant, 2005; Parr, Green, White, \& Sherlock, 2007) also are considered positive attributes of a wine. As such, use of these abstract terms, in particular quality and complexity, has potential to influence the prestige of a wine and the price that it can command.

Frequent use by wine critics of the terms quality and complexity when describing wines (e.g., Kramer, 2012) has not been accompanied by a similar degree of scientific investigation. Further, although quality and complexity in wine have been investigated individually, there is a gap in our understanding of how these important concepts are linked

\footnotetext{
* Corresponding author at: Department of Wine, Food \& Molecular Biosciences, Faculty of AGLS, P.O. Box 85084, Lincoln University, Lincoln 7647, Christchurch, New Zealand.

E-mail address: wendy.parr@lincoln.ac.nz (W.V. Parr).
} 
(Spence \& Wang, 2018), in particular by wine professionals whose role frequently involves making quality-related judgments (Parr, Green, \& White, 2006). The present study aims to remedy this, investigating wine professionals' perception of quality and complexity, their relation, and their association with an abstract attribute often considered important in fine wines such as Pinot noir, namely typicality (Ballester et al., 2005; Parr et al., 2007; Valentin et al., 2016). The aspect of typicality investigated in the current study was perceived, varietal typicality.

Wine is a complex beverage, both psychologically (Melcher \& Schooler, 1996) and in terms of its chemical composition (Thorngate, 1997). Perceiving the intrinsic attributes of a wine involves multisensory perception with visual, olfactory, taste and tactile phenomena integrating to drive a taster's judgments (Auvray \& Spence, 2008). Further, when the wine attributes being judged are somewhat abstract, the need for involvement of a taster's cognitive skill (e.g., prior knowledge) as well as multi-modal sensory processing is increased (Parr, 2019; Parr, Mouret, Blackmore, Pelquest-Hunt, \& Urdapilleta, 2011). Hence, judgments of the higher-order concepts (i.e., umbrella concepts) of quality, complexity, and varietal typicality are assumed to involve wine professionals' processes of conceptualisation, memory, judgment, and language as well as sensory and perceptual phenomena.

\subsection{Quality}

Quality in wine has a relatively short history in terms of explicit, scientific investigation (Charters \& Pettigrew, 2007; Lattey, Bramley, \& Francis, 2010; Saenz-Navajas et al., 2015; Valentin et al., 2016). These published studies, employing both qualitative (Charters \& Pettigrew, 2007) and quantitative (e.g., Valentin et al., 2016) methods, argue that quality, both perceived and conceptualised, constitutes a multi-dimensional concept with links to perceived complexity, and involving both intrinsic (e.g., perceived flavours; balance and harmony) and extrinsic (e.g., wine price; brand) factors (Valentin et al., 2016; Parr et al., 2011). In their study investigating wine professionals' quality judgments of Pinot noir wine, Valentin et al. (2016) reported that in-mouth attributes of overall balance and wine structure were the important drivers of perceived quality, along with varietal fruit attributes (e.g., red fruits; ripe fruit). Hence, as well as investigating varietally-important, aroma and taste attributes of Pinot noir wines as drivers of perceived quality and complexity, in the present study we considered textural attributes of Pinot noir wine reported as important by wine critics (Robinson, 2019) and scientists (Campo, Ballester, Langlois, Dacremont, \& Valentin, 2010; Valentin et al., 2016). The textural qualities investigated, as well as the taste of bitter, are assumed to have their source in wine chemical composition, notably phenolic composition (Frost, Harbertson, \& Heymann, 2017) as well as in human physiology (Laguna \& Sarkar, 2017). A complicating factor for sensory assessment of these attributes is that it is well established that perception of the taste of bitterness and of mouthfeel (trigeminal) qualities such as astringency varies amongst tasters, with large inter-individual differences often reported (e.g., Bartoshuk, 2000 for bitterness perception; Lesschaeve \& Noble, 2005 for perceived astringency and saliva differences).

\subsection{Complexity}

As with quality, perception of complexity in wine has received relatively little scientific attention (Parr, 2015; Spence \& Wang, 2018). Early work used the terms complexity and quality synonymously (Singleton \& Ough, 1962). More recently, complexity in the red wine Syrah was investigated by Meillon et al. (2010), using an innovative, 8item complexity questionnaire (Medel Maraboli, 2011), to investigate the sensory impact of reducing alcohol content in wines. The questionnaire comprised an overall quantitative judgment of complexity for each wine, along with judgments to seven other wine attributes assumed-to-be sub-components of perceived complexity. Subsequently, a study using a variant of the same questionnaire and the white wine Sauvignon blanc demonstrated the major attributes driving judgments of perceived complexity in Sauvignon blanc wines to be balance and harmony (Schlich et al., 2015). Neither study, however, included an assessment of overall quality of the same wines, leaving open the question concerning importance of perceived complexity in a wine to judgment of overall quality. Recently, Wang and Spence (2018) addressed this question in an empirical study involving social drinkers, demonstrating a positive relation between judgments of quality and complexity in a diverse selection of wine types ( $N=8$ wines in total). The present study extended this work by employing one wine variety only for assessment, namely Pinot noir, a larger wine sample set $(N=18)$, and by employing wine professionals experienced in producing and tasting Pinot noir wines as the assessors. Finally, although no wine tasting was involved such that the data represent participants' conceptualisation rather than perception, both Charters and Pettigrew (2007), in a qualitative study involving interview data, and Parr et al. (2011), using cerebral representation methodology with both wine professionals and consumers, reported a conceptual link between quality and complexity in wine. To substantiate behaviourally the link between experienced wine tasters' judgments of quality and complexity, in the present study we investigated these two concepts within a tasting context involving wine professionals.

\subsection{Typicality}

Also relevant to understanding wine professionals' perception of quality in a fine wine is the concept of typicality (Ballester et al., 2005; Parr et al., 2007). In many European countries, typicality is understood as the originality, uniqueness, and reputation of a product from a terroir or geographical location. For wine, as well as this regional or geographically-related typicality (e.g., Kustos et al., 2020), the concept of varietal typicality allows for assessment of a wine in terms of how well it matches expected characteristics of a particular grape variety (Parr, Valentin, Green, \& Dacremont, 2010). Typicality is a judgment requiring a degree of wine expertise to undertake validly (Sauvageot, 1994). In experimental situations, typicality is operationalised by asking tasters to judge wines in terms of the degree to which they are good examples of their grape variety and/or geographical location (Ballester et al., 2005; Parr et al., 2010). In their study with experienced French tasters, Parr et al. (2010) reported wine varietal typicality and wine liking to be closely correlated. More recently, typicality, liking and complexity were shown to be closely associated attributes in Sauvignon blanc wines (Parr et al., 2015) but unfortunately no data were collected concerning overall quality, leaving a gap in direct evidence of an association between perceived typicality, complexity, and quality. To our knowledge, the only published data linking wine professionals' assessments of perceived varietal typicality and perceived quality in Pinot noir wines are those reported by Valentin et al. (2016) where quality and typicality were closely related concepts for both Burgundian and New Zealand (NZ) tasters. In the present study, we investigate the importance of varietal typicality to experienced wine tasters' judgments of quality and complexity in Pinot noir wines.

\subsection{Colour influence}

The final factor we considered in some detail in the present study pertains to visual influence on perceived quality of Pinot noir wine. Vitis vinifera L cv. Pinot noir, often reported as "difficult" in terms of the challenges it affords both oenologists and viticulturists (Casassa et al., 2019), produces table wines commanding amongst the highest prices paid for bottled wine anywhere in the world. Despite its fine wine status, the phenolic composition of Pinot noir grapes and wine typically exhibits lower concentration of anthocyanins and tannins than many other well-known red varieties (Casassa et al., 2019; Mercurio, Dambergs, Cozzolino, Herderich, \& Smith, 2010). As a consequence, 
Table 1

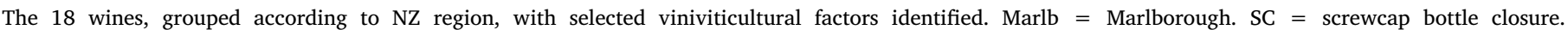

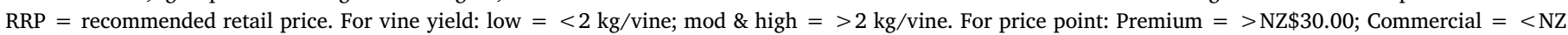
$\$ 30.00$.

\begin{tabular}{|c|c|c|c|c|c|c|c|}
\hline Wine identity & NZ Region & Vintage & Price point & Relative Vine yield & Production philosophy & Closure & RRP \$NZ \\
\hline WAR16 & Wairarapa & 2016 & Premium & Low & BioGro cert & SC & 82 \\
\hline WPP16 & Wairarapa & 2016 & Commercial & Mod & conventional & SC & 26 \\
\hline WPP13 & Wairarapa & 2013 & Commercial & Mod & conventional & SC & 26 \\
\hline WE16 & Wairarapa & 2016 & Premium & Low & Organic in transition & SC & 52 \\
\hline WCR16 & Wairarapa & 2016 & Premium & Low & conventional & SC & 140 \\
\hline MCH16 & Marlb & 2016 & Premium & Low & BioGro cert & Cork & 44 \\
\hline MPR16 & Marlb & 2016 & Commercial & High & conventional & SC & 15 \\
\hline MG16 & Marlb & 2016 & Premium & Low & BioGro cert & SC & 63 \\
\hline MG13 & Marlb & 2013 & Premium & Low & BioGro cert & SC & 63 \\
\hline OMD16 & Central Otago & 2016 & Commercial & High & conventional & SC & 28 \\
\hline OFRCP16 & Central Otago & 2016 & Premium & Low & Demeter cert & SC & 76 \\
\hline OFRB316 & Central Otago & 2016 & Premium & Low & Demeter cert & SC & 102 \\
\hline OQR16 & Central Otago & 2016 & Premium & Low & BioGro \& Demeter cert & SC & 79 \\
\hline OQR13 & Central Otago & 2013 & Premium & Low & BioGro \& Demeter cert & SC & 79 \\
\hline NN16 & Nelson & 2016 & Premium & Low & BioGro cert & SC & 67 \\
\hline NS16 & Nelson & 2016 & Commercial & High & conventional & SC & 13 \\
\hline СРB16 & Nth Canterbury & 2016 & Commercial & Mod & conventional & SC & 22 \\
\hline CG16 & Nth Canterbury & 2016 & Premium & Low & organic in transition & SC & 43 \\
\hline
\end{tabular}

Pinot noir wines tend toward the lighter end of the red table wine spectrum in terms of colour, with anecdotal evidence and wine-show data (Dambergs, 2012) suggesting the lighter colour to adversely affect chemosensory assessment of Pinot noir wines by both consumers and wine professionals (Mercurio et al., 2010). This is in keeping with research demonstrating that the colour of a food or beverage can influence both qualitative and quantitative aspects of perceived odour, aroma and taste (Kemp \& Gilbert, 1997; Morrot, Brochet, \& Dubourdieu, 2001; Pangborn, Berg, \& Hansen, 1963; Parr, White, \& Heatherbell, 2003; Spence, Levitan, Shankar, \& Zampini, 2010; Stillman, 1993; Zellner \& Whitten, 1999; Zellner, 2013). Further, expertise in a domain such as wine does not necessarily prevent colourdriven, olfactory bias (Parr et al., 2003). In terms of colour influence on perceived quality judgments, a wine's appearance was reported as a contributor to the overall quality construct of Spanish red wines by Saenz-Navajas et al. (2016) in a study with experienced tasters, and by Charters and Pettigrew (2007) in a qualitative study involving consumers with different levels of wine involvement. On the other hand, Valentin et al. (2016) demonstrated that wine colour was not a major driver of French and NZ wine professionals' chemosensory judgments of French and NZ Pinot noir wines. The authors interpreted this latter result as having its source in wine professionals' knowledge and experience relative to that of consumers (Parr et al., 2011), with wine professionals' domain-specific expertise affording them awareness that lightness of colour does not necessarily exclude a wine from being complex in nature and of high quality. To clarify the importance of colour on perception of Pinot noir wine quality by wine professionals, and to extend the exploration of wine colour influence to judgments of complexity and typicality, colour influence was assessed indirectly in the present study. Each taster experienced each wine in both clear and opaque glassware, the latter context prohibiting visual cues that have been demonstrated to produce colour bias.

\section{Research aims}

The overall aim of the present study was to extend current knowledge about perception of quality in red wine. More specifically, the study aimed to understand the intrinsic, chemosensory wine attributes driving wine professionals' perception of quality, complexity, and varietal typicality in Pinot noir wines, and the relation between these higher-order concepts. Hence, we investigated: (i) wine attributes driving quality judgments, (ii) wine attributes driving complexity judgments, (iii) the relation between complexity and quality, (iv) the importance of perceived varietal typicality to quality and complexity judgments, and (v) influence of tasting-glass colour on Pinot noir chemosensory judgments.

\section{Materials and methods}

\subsection{Participants}

Twenty-two NZ-based wine professionals participated in the sensory study. All participants were experienced with production and tasting of Pinot noir wine and were considered to be wine experts as defined by Parr, Heatherbell, and White (2002, p. 748). That is, they were known to be employed in Pinot noir wine production, their overall expertise exemplified in that the mean number of years of wine industry experience was 18.2 years (range: 3-40 years). Participants were primarily oenologists and winemakers $(N=19)$, two defined their major activity as viticulturist, and one participant was a cellar hand. Mean age of the participants was 42.7 years (age range: 33-62) and there were 6 females and 16 males. Nine of the 22 participants reported formal wine judging experience. No participants reported that they were smokers. Participants were not subjected to any form of training prior to their participation in the current study. Several participants had however attended one or more research tastings related to prior experiments (e.g., Parr et al., 2015) and were familiar with the environmental controls (e.g., individual booths) and methodological requirements such as type of rating scales employed.

\subsection{Wines}

Eighteen NZ, commercial Pinot noir wines were employed in the study (see Table 1), 15 from the 2016 vintage and 3 from the 2013 vintage. Four producers had two wines each in the 18-wine sample set, and each of the other 10 wines was produced by a different company. The 2013 wines were prior vintages from producers of three of the 2016 wines. The wines were selected from a larger sample set of wines that had been evaluated in a pilot tasting by an expert panel of senior NZ wine professionals $(\mathrm{N}=11)$ six months' previously. No participant in the current study had participated in the expert-panel, pre-experimental, pilot tasting. The wines were evaluated in the pilot tasting to ensure that the final selection of wines: (i) spanned a range in terms of recommended retail price, Pinot noir perceived quality, wine style (e.g., production methods) and colour; and (ii), represented the five major, Pinot-noir producing areas of NZ, and included a vintage older than 
that currently dominating the NZ commercial marketplace (i.e., 2016 vintage). The 18 wines were selected to span a range of assumed quality categories, quality operationally defined a priori by recommended retail price, this ranging between NZ\$13.00 and NZ\$140.00. The viniviticultural variables reported in Table 1 (e.g., wine region; vine yield) were controlling factors, ensuring that a representative sample of NZ wines was employed in the experiment. They were not treated as independent variables in the present study for valid reasons (e.g., small and unequal numbers in some cells).

\subsection{Experimental design}

The within-subject design involved participants evaluating each wine in two sessions (Session 1: wine assessment in clear glasses; Session 2: wine assessment in opaque glasses) with session order controlled by 9 participants undertaking Session 1 first followed by Session 2 and the remainder of the participants undertaking Session 2 first followed by Session 1 .

\subsection{Procedure}

The sensory study was conducted at the Marlborough Wine Research Centre (MWRC) in NZ in late 2018. Three to five people participated at any particular time. Participants were welcomed to the sensory facilities and seated in separate booths. The environment of the sensory facilities was controlled as advised for sensory experimentation (ASTM, 1986). Participants were provided with basic information about the study, following which they completed forms in keeping with ethical requirements of Lincoln University, NZ. They were advised that they would taste and make judgments about eighteen wines and that all wines were Pinot noir. They were not given any other information about the study, and were not subjected to any form of training (e.g., provision of reference standards or a lexicon).

The wines were served at room temperature. A new bottle of each wine was opened each day that the experiment was conducted and the wines were first checked for faults by two or three experienced wine professionals. The wine samples for each stage of the task comprised $50-\mathrm{ml}$, with a new sample poured for each of the two chemosensory evaluations within each session. In Session 1, the wine samples were served in clear, Spiegelau tasting glasses (Spiegelau \# 44001 31) while in Session 2 the wines were served in black (opaque) Spiegelau tasting glasses (Spiegelau \# 44085 31). The glasses were coded with 3-digit numbers and were covered with plastic Petri dishes. In order to limit carry over effects and memory biases, all wine samples were presented in a different order specific to each participant within each session and between sessions according to a Williams Latin square arrangement generated by FIZZ software (Biosystemes, Courtenon, France). Water and plain water crackers were available throughout each session.

Participants undertook both their sessions on the same day with the two sessions separated by an interval of approximately $20 \mathrm{~min}$. They were advised that they were to evaluate each wine in the order presented, and that all wine was to be expectorated (i.e., not swallowed). Sessions 1 and 2 were identical procedurally apart from glass colour and wine order. Each participant first rated the wines on the twenty, experimenter-provided descriptors reported in Table 2. The 20 descriptors were selected as appropriate for sensory characterisation of Pinot noir wines (Tomasino, Harrison, Sedcole, \& Frost, 2013), and included wine characters assumed capable of assisting in differentiating wines of varying phenolic composition (e.g., ripe fruit; astringency; silkiness; structure) and perceived quality (Valentin et al., 2016). The 20 wine attributes for descriptive rating were separated into two groups as shown in Table 2. The first group, labelled intensity descriptors, included attributes that correspond to unidimensional, specific sensory terms. These descriptors are assumed to provide information on perceived intensity of specific characteristics of the wines. This type of evaluation reflects what is often called analytical assessment. The
Table 2

Wine attributes rated as descriptors of Pinot noir wine.

\begin{tabular}{ll}
\hline Descriptors & Scale anchors \\
\hline Intensity descriptors & \\
Attractive fruit aromatics & Low-Intense \\
Attractive floral aromatics & Low-Intense \\
Earthy/mushroom notes & Low-Intense \\
Reductive notes & Low-Intense \\
Bitterness & Low-Intense \\
Astringency & Low-Intense \\
Sweetness & Low-Intense \\
Harshness of tannins & Low-intense \\
Green/herbaceous notes & Low-intense \\
Quality evaluation & \\
Overall quality & \\
Balanced acidity & Poor-Good \\
Elegance/precision & Poor-Good \\
Softness/silkiness & Poor-Good \\
Freshness & Poor-Good \\
Expressiveness & Poor-Good \\
Fruit ripeness & Poor-Good \\
Oak influence & Poor - Good \\
Concentration in mouth & Poor-Good \\
Overall structure & Poor-Good \\
Pinot noir varietal typicality & Poor-Good \\
& Poor-Good \\
\hline &
\end{tabular}

second group of attributes, labelled quality evaluation, involved descriptors requiring holistic, multi-modal, sensorial processing and provide information on the judges' perception of overall wine quality, along with other less-concrete attributes. This latter type of evaluation is often termed 'global' assessment (Parr et al., 2015). The attributes were scored on 10-point scales with each scale's anchors as described in Table 2 . The descriptors were rated in the same order by each participant and in each condition, with overall quality the first attribute to be rated and varietal typicality the last item to be rated.

After participants had completed rating the 20 descriptors, their data sheets were collected by an experimenter and replaced with an 8item Complexity Questionnaire (Schlich et al., 2015). The complexity questionnaire, developed in French (Medel Maraboli, 2011), was subsequently translated and used in English (Schlich et al., 2015). The complexity questionnaire (see Fig. 1) comprises an overall quantitative judgment of complexity for each wine, and ratings to seven assumed sub-components of perceived complexity. The eight continuous scales (1-100 on a $100 \mathrm{~mm}$ line scale) are anchored with pictures, these aimed at clarifying the concept under evaluation. The seven assumed attributes of perceived complexity in wine include wine familiarity, number of perceptible flavours, ease of identification of the separate flavours, harmony, balance, persistence of wine in mouth (length), and concentration (strength of flavour). Of particular importance, the questionnaire contains items that investigate perceived blendedness (e.g., evaluation of harmony) or lack of blendedness (e.g., ease of identifying the different flavours/components), these notions of theoretical interest to understanding perceived complexity (Schlich et al., 2015).

\subsection{Physico-chemical methods}

\subsubsection{Wine standard parameters}

Wine samples were taken from each of the 18 wines for physicochemical analysis of standard wine parameters (Table 3). The wine parameters in the table were determined at the NZ Institute of Plant and Food Research (PFR) analytical laboratory. Wine alcohol was measured using an Anton Paar wine alcolyser (Graz, Austria), all measurements taken in duplicate with $<0.02 \mathrm{v} / \mathrm{v} \%$ variation. Titratable acidity and $\mathrm{pH}$ were determined using a Mettler Toledo (Columbus, Ohio, USA) T70 autotitrator with an end-point titration to $\mathrm{pH}$ 8.2. Aqueous sodium hydroxide $(0.1 \mathrm{M})$ was used as the titrant. Samples were degassed prior to analysis. Glucose and fructose were quantified by enzymatic assay 
Panelist :

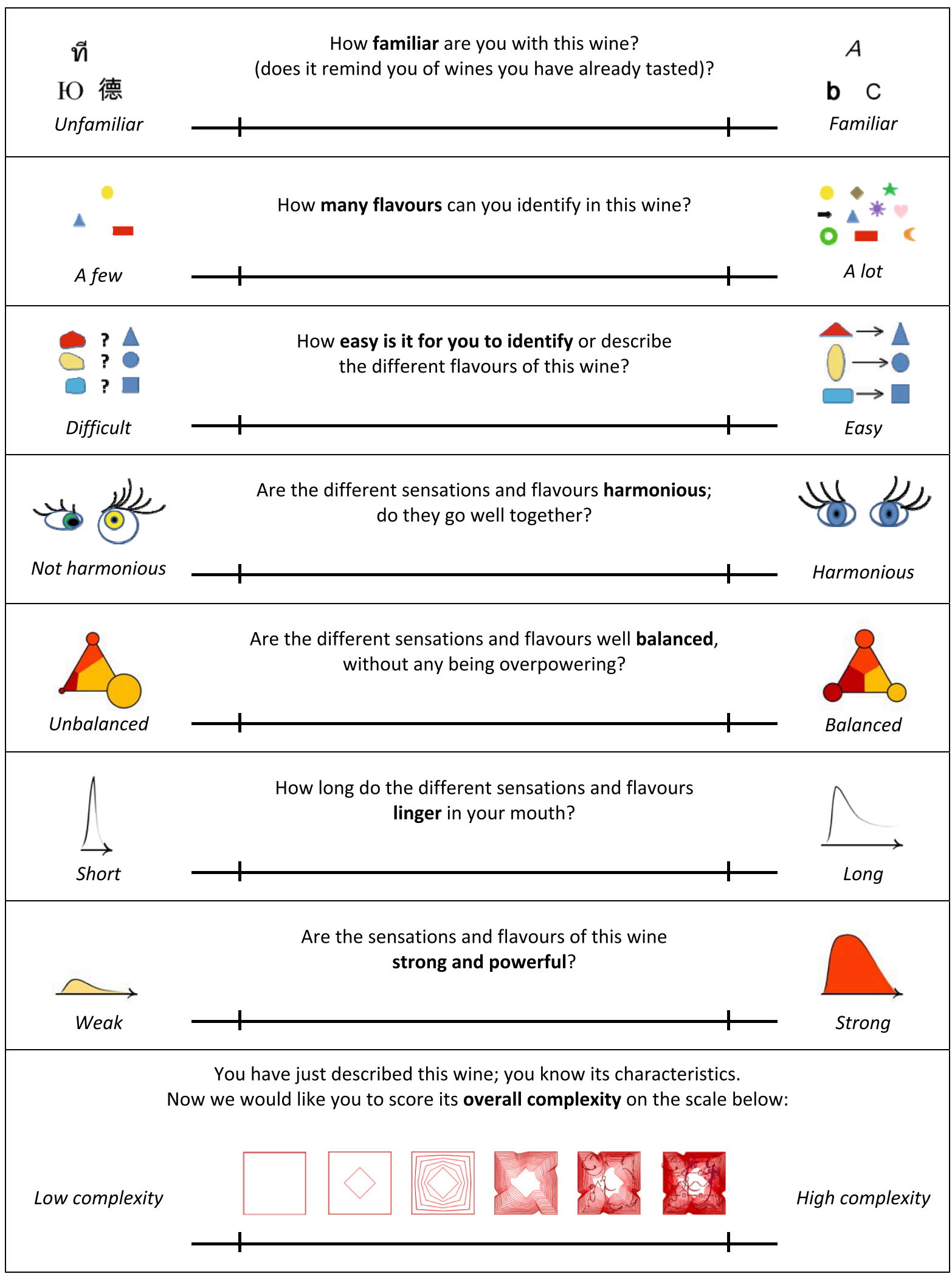

Fig. 1. The 8-item Complexity Questionnaire employed in the experiment.

based on the reduction of NADP to NADPH, the reaction monitored at $340 \mathrm{~nm}$ using a Molecular Devices (San Jose, California, USA) Spectramax 384 Plus plate reader with a $1-\mathrm{cm}$ pathlength cuvette reference correction. Enzymes and cofactors were purchased from Megazyme (Bray, Ireland). Samples were appropriately diluted and quantified in duplicate against an eight-point standard curve $\left(R^{2}>0.98\right)$. This 
Table 3

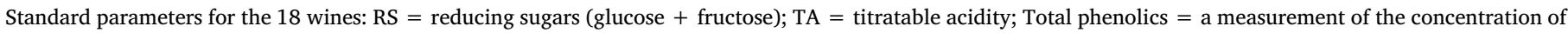

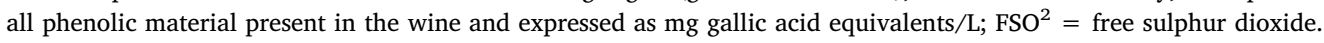

\begin{tabular}{|c|c|c|c|c|c|c|c|}
\hline Wine identity & $\mathrm{RS}(\mathrm{g} / \mathrm{L})$ & Ethanol (v/v \%) & $\mathrm{pH}$ & TA $(\mathrm{g} / \mathrm{L})$ & Total Phenolics (mgGAE/L) & FSO2 (PPM) & Total SO2 (PPM) \\
\hline \multirow[t]{2}{*}{ WAR16 } & 0.33 & 13.74 & 3.72 & 4.61 & 2230 & 14.4 & 49.6 \\
\hline & $(0.03)$ & $(0.02)$ & {$[0.00]$} & {$[0.03]$} & $(9.7)$ & {$[0.41]$} & {$[0.41]$} \\
\hline \multirow[t]{2}{*}{ WPP16 } & 0.52 & 14.16 & 3.60 & 5.15 & 2581 & 15.2 & 51.2 \\
\hline & $(0.03)$ & $(0.01)$ & {$[0.00]$} & {$[0.03]$} & $(54.9)$ & {$[0.41]$} & {$[0.41]$} \\
\hline \multirow[t]{2}{*}{ WPP13 } & 0.66 & 14.29 & 3.50 & 5.4 & 2433 & 9.6 & 44.8 \\
\hline & $(0.27)$ & $(0.01)$ & {$[0.00]$} & {$[0.03]$} & $(261)$ & {$[0.41]$} & {$[0.41]$} \\
\hline \multirow[t]{2}{*}{ WE16 } & 0.30 & 14.26 & 3.52 & 5.55 & 2155 & 12.8 & 37.6 \\
\hline & $(0.02)$ & $(0.02)$ & {$[0.00]$} & {$[0.03]$} & $(13.2)$ & {$[0.41]$} & {$[0.41]$} \\
\hline \multirow[t]{2}{*}{ WCR16 } & 0.48 & 14.32 & 3.53 & 5.36 & 1657 & 11.2 & 35.2 \\
\hline & $(0.03)$ & $(0.01)$ & {$[0.00]$} & {$[0.03]$} & (19.8) & {$[0.41]$} & {$[0.41]$} \\
\hline \multirow[t]{2}{*}{ MCH16 } & 0.30 & 13.92 & 3.61 & 4.98 & 1615 & 6.4 & 57.6 \\
\hline & $(0.01)$ & $(0.01)$ & {$[0.00]$} & {$[0.03]$} & (23.7) & {$[0.41]$} & {$[0.41]$} \\
\hline \multirow[t]{2}{*}{ MPR16 } & 0.54 & 13.36 & 3.55 & 5.43 & 1785 & 17.6 & 96.0 \\
\hline & $(0.03)$ & $(0.01)$ & {$[0.00]$} & {$[0.03]$} & $(30.5)$ & {$[0.41]$} & {$[0.41]$} \\
\hline \multirow[t]{2}{*}{ MG16 } & 0.47 & 12.75 & 3.43 & 5.04 & 1058 & 6.4 & 59.2 \\
\hline & $(0.06)$ & $(0.01)$ & {$[0.00]$} & {$[0.03]$} & $(38.0)$ & {$[0.41]$} & {$[0.41]$} \\
\hline \multirow[t]{2}{*}{ MG13 } & 0.53 & 14.78 & 3.60 & 5.17 & 1917 & 4.0 & 30.4 \\
\hline & $(0.04)$ & $(0.00)$ & {$[0.00]$} & {$[0.03]$} & (3.1) & {$[0.41]$} & {$[0.41]$} \\
\hline \multirow[t]{2}{*}{ OMD16 } & 0.27 & 13.97 & 3.70 & 5.19 & 1796 & 12.8 & 40.0 \\
\hline & $(0.02)$ & $(0.04)$ & {$[0.00]$} & {$[0.03]$} & (33.0) & {$[0.41]$} & {$[0.41]$} \\
\hline \multirow[t]{2}{*}{ OFRCP16 } & 0.32 & 13.99 & 3.73 & 4.63 & 1288 & 20.8 & 52.8 \\
\hline & $(0.02)$ & $(0.01)$ & {$[0.00]$} & {$[0.03]$} & $(4.4)$ & {$[0.41]$} & {$[0.41]$} \\
\hline \multirow[t]{2}{*}{ OFRB316 } & 0.41 & 13.47 & 3.72 & 4.62 & 1312 & 12.0 & 49.6 \\
\hline & $(0.01)$ & $(0.01)$ & {$[0.00]$} & {$[0.03]$} & $(8.1)$ & {$[0.41]$} & {$[0.41]$} \\
\hline \multirow[t]{2}{*}{ OQR16 } & 0.69 & 13.83 & 3.65 & 4.95 & 1116 & 25.6 & 62.4 \\
\hline & (0.09) & $(0.00)$ & {$[0.00]$} & {$[0.03]$} & (5.6) & {$[0.41]$} & {$[0.41]$} \\
\hline \multirow[t]{2}{*}{ OQR13 } & 0.33 & 14.43 & 3.66 & 4.87 & 2450 & 4.8 & 33.6 \\
\hline & $(0.06)$ & $(0.01)$ & {$[0.00]$} & {$[0.03]$} & (21.4) & {$[0.41]$} & {$[0.41]$} \\
\hline \multirow[t]{2}{*}{ NN16 } & 0.38 & 12.26 & 3.77 & 4.70 & 1656 & 16.0 & 80.0 \\
\hline & $(0.02)$ & $(0.01)$ & {$[0.00]$} & {$[0.03]$} & $(8.2)$ & {$[0.41]$} & {$[0.41]$} \\
\hline \multirow[t]{2}{*}{ NS16 } & 1.17 & 13.20 & 3.77 & 5.33 & 1392 & 11.2 & 51.2 \\
\hline & $(0.02)$ & $(0.01)$ & {$[0.00]$} & {$[0.03]$} & $(0.8)$ & {$[0.41]$} & {$[0.41]$} \\
\hline \multirow[t]{2}{*}{ СРB16 } & 0.48 & 14.54 & 3.66 & 5.49 & 2027 & 16.0 & 52.8 \\
\hline & $(0.01)$ & $(0.01)$ & {$[0.00]$} & {$[0.03]$} & $(4.0)$ & {$[0.41]$} & {$[0.41]$} \\
\hline \multirow[t]{2}{*}{ CG16 } & 0.23 & 13.97 & 3.67 & 5.09 & 2146 & 11.2 & 48.0 \\
\hline & $(0.02)$ & $(0.01)$ & {$[0.00]$} & {$[0.03]$} & $(7.0)$ & {$[0.41]$} & {$[0.41]$} \\
\hline
\end{tabular}

Values in parentheses () are standard deviations of the analysis duplicates for this assay.

Values in parentheses [] are an average of the standard deviations of quality control analysis duplicates for this assay.

method is adapted from the Compendium of International Methods of Analysis OIV-MA-AS311-02. Sample optical density was measured directly in a UV transparent 96 -well microplate at $280 \mathrm{~nm}$ using the plate reader. Absorbance at $280 \mathrm{~nm}$ was used to quantify total polyphenols against a five-point gallic acid standard curve $\left(\mathrm{R}^{2}>0.98\right)$ (method adapted from that of Somers \& Evans, 1977). All samples were measured in duplicate. Free and total sulphur dioxide $\left(\mathrm{SO}_{2}\right)$ were estimated using published methodology, namely the aspiration method. Sulphur dioxide was sparged from an acidified wine sample in an air stream and trapped in a solution of hydrogen peroxide which oxidises the sulphur dioxide to sulphuric acid. The sulphuric acid formed was then titrated with standardised sodium hydroxide, and the amount used is proportional to the amount of sulphur dioxide in the wine. Total sulphur dioxide was determined by heating an acidified sample during the aspiration step (Rankin \& Pocock, 1970).

\subsubsection{UV-Spectrophotometer measures of wine colour}

Wine colour analysis was conducted using a UNICAM Helios Gamma UV-Vis spectrophotometer (Thermo Spectronic, England). Widely-used spectral measures of wine colour were recorded as follows. For $\mathrm{A}_{520}^{\mathrm{SO}_{2}}: 30 \mu \mathrm{L}$ of $10 \%$ potassium metabisulphite solution was added to the wine in a test tube, which was then covered with laboratory film and mixed thoroughly. For $\mathrm{A}_{280}$ : $10 \mathrm{~mL}$ of $1 \mathrm{M} \mathrm{HCl}$ solution was pipetted into a test tube, then, using a micropipettor $100 \mu \mathrm{L}$ of wine was added, before being covered with laboratory film, mixed thoroughly and left for at least $1 \mathrm{~h}$ prior to taking the reading. The absorbance readings at $420 \mathrm{~nm}$ and $520 \mathrm{~nm}$ were measured using $2 \mathrm{~mm}$ path length cuvettes (UVette, Eppendorf, Germany). The absorbance of the solution at $280 \mathrm{~nm}$ was measured in a $10 \mathrm{~mm}$ quartz cuvette. Wine colour density was calculated as $A_{520}+A_{420}$ (red colour plus yellow-brown colour) and wine hue as $A_{420} / A_{520}$ (ratio of brown to red pigments). The spectrophotometric measures for the Pinot noir wines taken at $420 \mathrm{~nm}$ and $520 \mathrm{~nm}$ (for wine colour), and at $520 \mathrm{~nm}$ after bleaching with excess sulphite, are provided in Supplementary Materials (Table S1).

\subsection{Data analysis}

\subsubsection{Influence of tasting-glass colour on Pinot noir chemosensory judgment}

To consider the within-participant effect of glass colour on wine attribute ratings (intensity; quality; complexity), Analyses of Variance (ANOVAs, using R packages lme4 and predictmeans) were conducted with evaluation condition (clear vs black tasting glasses) and wine as fixed factors and participant as a random factor. A significance level of 0.05 was adopted for all analyses.

\subsubsection{Association of sensory and instrumental colour data}

The two replicates of the UV-Spectrophotometer colour measurements for density and for hue were quantitatively close, in particular compared to the difference between wines. Pearson correlation coefficients were computed to correlate the mean spectrophotometer colour measures of density and of hue for each wine with the mean scores from the clear-glass, sensory condition. 
Table 4

Mean UV-Spectro colour measures for Density and Hue correlated with mean sensory rating results from Clear Glass condition. Attributes statistically significant at $p<0.05$ are in bold face.

\begin{tabular}{|c|c|c|}
\hline & Density & Hue \\
\hline \multicolumn{3}{|l|}{ Intensity attribute } \\
\hline Attractive fruit aromatics & 0.57 & -0.73 \\
\hline Attractive floral aromatics & 0.52 & -0.60 \\
\hline Sweetness & 0.22 & -0.62 \\
\hline Bitterness & 0.52 & -0.20 \\
\hline Harshness of tannins & 0.57 & -0.11 \\
\hline Astringency & 0.46 & -0.08 \\
\hline Green herbaceous & 0.34 & 0.00 \\
\hline Earthy mushroom & -0.06 & 0.30 \\
\hline Reductive notes & -0.49 & 0.42 \\
\hline \multicolumn{3}{|l|}{ Quality attribute } \\
\hline Concentration in mouth & 0.72 & -0.71 \\
\hline Freshness & 0.49 & -0.78 \\
\hline Expressiveness & 0.54 & -0.64 \\
\hline Oak influence & 0.50 & -0.51 \\
\hline Fruit ripeness & 0.43 & -0.56 \\
\hline Overall structure & 0.41 & -0.52 \\
\hline Overall Quality & 0.34 & -0.51 \\
\hline Varietal typicality & 0.17 & -0.48 \\
\hline Balanced acidity & 0.10 & -0.18 \\
\hline Elegance precision & -0.23 & -0.19 \\
\hline Softness silkiness & -0.36 & -0.09 \\
\hline \multicolumn{3}{|l|}{ Complexity attribute } \\
\hline Strength of flavour & 0.70 & -0.64 \\
\hline Length & 0.67 & -0.51 \\
\hline Number of flavours able to be identified & 0.48 & -0.58 \\
\hline Overall Complexity & 0.31 & -0.52 \\
\hline Familiarity & 0.27 & -0.53 \\
\hline Ease of identifying wine attributes & 0.29 & -0.44 \\
\hline Harmony & 0.06 & -0.43 \\
\hline Balance & 0.01 & -0.41 \\
\hline
\end{tabular}

3.6.3. Relationship between intensity, quality and complexity judgments

Two Multiple Factor Analyses (MFA) were carried out, one for each tasting condition (clear vs black glasses), on all chemosensory assessments. Intensity, quality, and complexity attributes were entered in the analysis as active blocks. Analyses were done on the correlation matrices (SPAD, 9.1).

\section{Results}

\subsection{Influence of tasting-glass colour on Pinot noir chemosensory judgment}

\subsubsection{Intensity descriptors}

A significant main effect of Wine was observed for all intensity attributes demonstrating that participants perceived the wines as differing across sensory descriptors $(p<0.001)$. There were no significant Wine $\times$ Glass-colour interactions and Glass Colour had a significant effect ( $p=0.030)$ on the green/herbaceous descriptor only. The green/ herbaceous attribute, typically considered not desirable in fine Pinot noir wine, was rated significantly lower when wine colour was visible (mean $=4.27$ in black glass vs 3.99 in clear glass). Means and SDs for rated attributes are reported in Supplementary Materials (Table S2).

\subsubsection{Quality evaluation}

A significant main effect of Wine was observed for all quality attributes except balanced acidity $(p=0.098)$ and oak influence $(p=0.123)$. Again, there was no significant Wine $\times$ Glass Colour interaction but Glass Colour was significant for seven of the eleven descriptors. Each of these seven quality attributes was rated lower when the wines were in black glasses: overall quality (mean $=5.61$ vs 5.97 in clear, $p=0.005$ ); elegance/precision (mean $=4.95$ vs 5.27 in clear, $p=0.018$ ); soft/silkiness (mean $=5.21$ vs 5.46 in clear, $p=0.049$ ); fruit ripeness (mean $=6.07$ vs 6.34 in clear, $p=0.028$ ); concentration in mouth (mean $=5.91$ vs 6.33 in clear, $p=0.001$ ); overall structure (mean $=5.77$ vs 6.07 in clear, $p=0.021$ ); and varietal typicality (mean $=5.94$ vs 6.27 in clear, $p=0.007$ ). These results are remarkably similar to the glass-colour effects reported by Valentin et al. (2016: Table 6) in a study involving French and NZ Pinot noir wines. Failure of any Wine $\times$ Glass-colour interactions to reach significance suggests that the glass-colour effect applied similarly to all the wines.

\subsubsection{Complexity evaluation}

ANOVA results showed all eight complexity-questionnaire characteristics to differ significantly among wines, $p<0.001$, except for ease of identifying flavours, $p=0.013$. Number of flavours differed significantly due to glass colour ( $M=56.5$ vs 54.3 in clear, $p=0.036$ ).

Familiarity and strength of flavour showed significant Wine $\times$ Glass Colour interactions ( $p=0.025$ and 0.008 , respectively). Although these two complexity attributes were rated similarly for the majority of wines, for a small number of wines, glass colour was influential. In terms of familiarity, wine WAR16 was judged more familiar in the clear glass, while wines NN16 and NS16 were judged less familiar when in a clear glass. Strength of flavour was judged higher in clear glasses for WCR16 and OQR13, and lower in clear glasses for wines NN16 and NS16.

\subsubsection{Association of sensory and instrumental colour measures}

The spectrophotometric measures obtained, reported in Supplementary Material, lay within the ranges obtained for past surveys of red wines that included Pinot noir wines (Cliff \& Dever, 1996; De Beer et al., 2004). The total colour density $\left(A_{420}+A_{520}\right)$ values varied by a factor of 2.5 (1.1-2.7) across the wine set, and the wines with the lowest values were visibly lighter in colour. The non-bleachable pigments (NBP) represented on average $69 \%$ of the $520 \mathrm{~nm}$ colour. As expected, this value (78-80\%) was higher in the 2013 wines where a greater loss of bleachable monomeric anthocyanins is expected to have occurred. The colour hue $\left(\mathrm{A}_{420} / \mathrm{A}_{520}\right)$ values averaged 1.0, and the wines with the largest hue values were also visibly the most brown.

Several wine attributes were scored differently according to whether the wine's colour could be seen or not. Correlations between the mean colour measures for each wine with the mean descriptive rating scores (intensity and quality attributes) from the clear-glass condition are reported in Table 4. The colour measures (Density and Hue) were negatively correlated $(r=-0.69)$ so in general measures that were correlated with one were also correlated with the other. Most attributes (19 out of 28) showed some significant correlation with colour.

\subsection{Relationship between intensity, quality and complexity judgments}

Figs. 2 and 3 present the projections of the intensity, quality and complexity attributes and wines onto the first MFA two-dimensional space in the clear glass (70\% of variance) and black glass conditions ( $61 \%$ of variance), respectively. A first glance at the two figures shows a high similarity between the two conditions $(R V=0.81)$.

In both glass-colour conditions, all quality and complexity scores project positively onto the first PC, the wines with highest quality and complexity on the right side opposing the wines with lower quality on the left. Attributes of varietal typicality, complexity and quality thus appear closely related concepts. The Pearson correlations between them are high: typicality and complexity, $r=0.71$ in clear glasses and 0.61 in dark; typicality and quality, $r=0.90$ in clear glasses and 0.86 in dark; complexity and quality, $r=0.73$ in clear glasses and 0.61 in dark. Although the correlations are slightly lower in the black glasses than in the clear-glass condition, the observed differences are not significant (Fisher's $z$ transformation; the differences are all about 1 SD on the transformed scale) and all coefficients are significantly different from zero (Alpha $=5 \%$ ).

In both glass-colour conditions, with the exception of three attributes (attractive floral aromatics, attractive fruit aromatics, and 


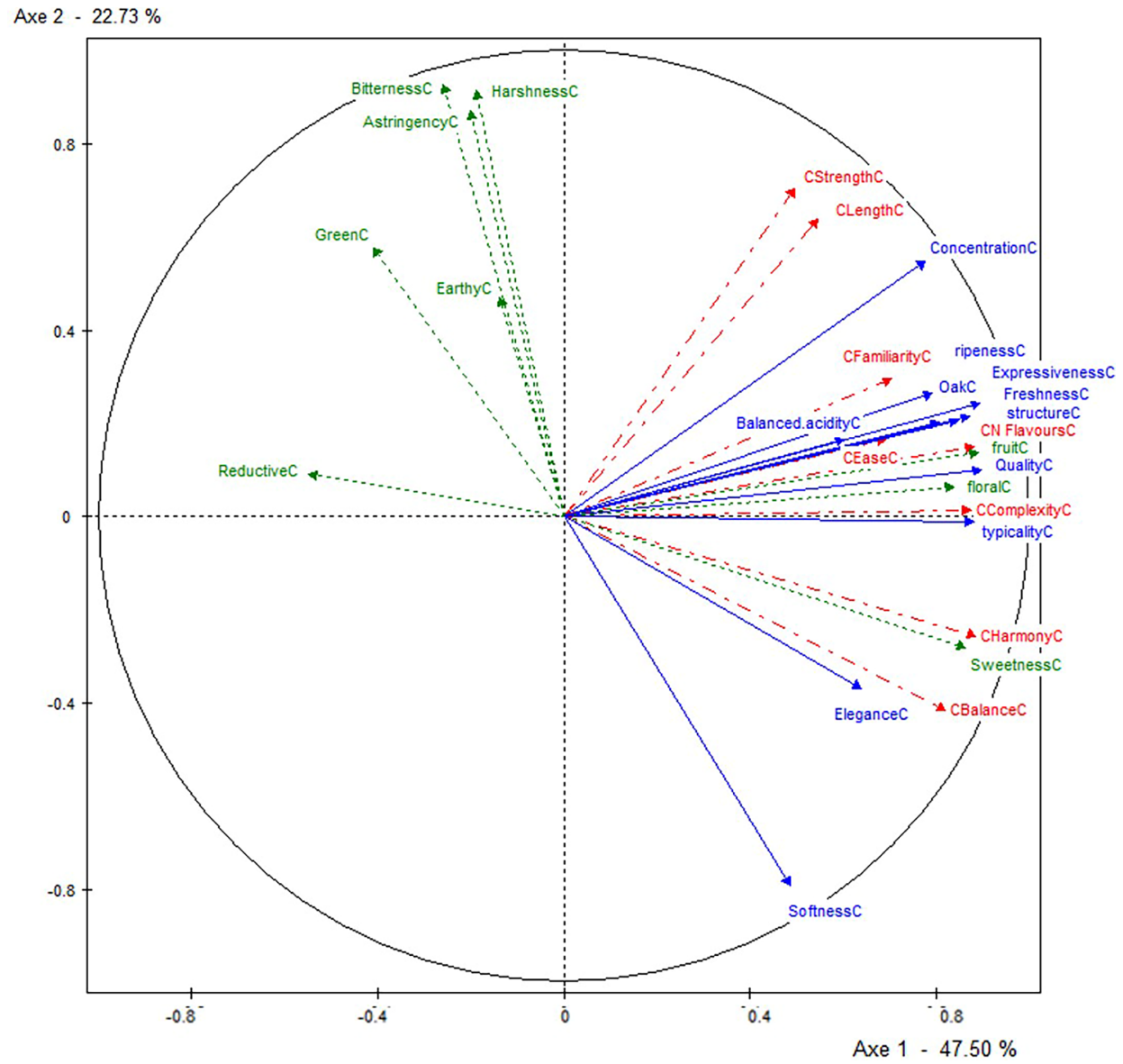

Fig. 2a. Representation of the attributes (dotted line = intensity; solid line = quality; dashed line = complexity) on the first two dimensions of the MFA in the clear glass condition.

sweetness), complexity and quality attributes seem to be somewhat independent of the other chemosensory attributes, which for the most part load on the second dimension. This is particularly true for the textural attributes (e.g., astringency; harshness of tannins) and the taste of bitterness.

In Figs. 2 and 3, the most conspicuous difference between the clear glass and black glass conditions concerns wine NS16. On the clear glass map, this wine separates out from the other samples (from OFRCP16 to OQR13), scoring lower than most other wines in terms of several attributes including harshness of tannins and attractive aromatics. On the black-glass map, where visual influence driven by wine attributes such as colour and clarity is denied, wine NS16 is part of the crowd of wines, albeit still judged somewhat low in terms of attractive aromatics, but moderate in terms of harshness of tannins, while wine MPR16 separates out, being high in reductive notes and low in attractive aromatics. Wines NS16 and MPR16 were the two lowest-priced wines in the 18wine, sample set, and these two wines were also the lowest in colour density, and the most brown (higher hue values).

\subsection{Wine attributes driving quality judgments}

Given the major aim of this study, we correlated the mean overall quality scores for each wine with the mean scores of the other wine attributes separately in the clear and black glass conditions to highlight wine attributes driving overall perceived quality (Table 5). For both conditions, the highest positive correlations were with varietal typicality, expressiveness, overall structure and attractive fruit aromatics while the highest negative correlation was with reductive notes. Some differences between conditions can be noted: in the clear-glass condition, fruit ripeness, oak influence, attractive floral aromatics and sweetness were more positively correlated while green herbaceous was more negatively correlated with overall perceived quality than in the black glass condition.

All eight complexity-questionnaire characteristics were positively correlated with overall perceived quality. In both evaluation conditions, the higher correlations were found for harmony, balance, number of flavours identifiable, and familiarity. In the clear glass condition, number of flavours was more highly correlated with overall perceived quality than in the black glass condition. No other differences were observed between conditions.

\subsection{Wine attributes driving complexity judgments}

To highlight wine attributes driving perceived complexity, we correlated mean wine attribute, descriptive rating scores with mean overall complexity scores for each wine separately in the clear and black glass condition (Table 6). Several wine attributes contributed positively to the overall complexity judgment in both conditions, namely overall structure, expressiveness, elegance/precision, concentration in mouth, freshness, and balanced acidity. For the other attributes, some differences were observed between the two conditions. In particular, complexity was significantly, negatively correlated to harshness of tannins, bitterness and astringency and positively to softness/silkiness in the black glass condition but not in the clear glass condition. For attributes attractive fruit and floral aromatics, oak influence, varietal typicality, sweetness, and fruit ripeness, the correlations were higher in the clear glass than in the black glass condition. Finally, and in terms of the major aims of the present study, the correlation results presented above demonstrate that varietal typicality is more closely associated with perceived quality (Table 5) than with perceived complexity (Table 6). 
Axe $2-22.73 \%$

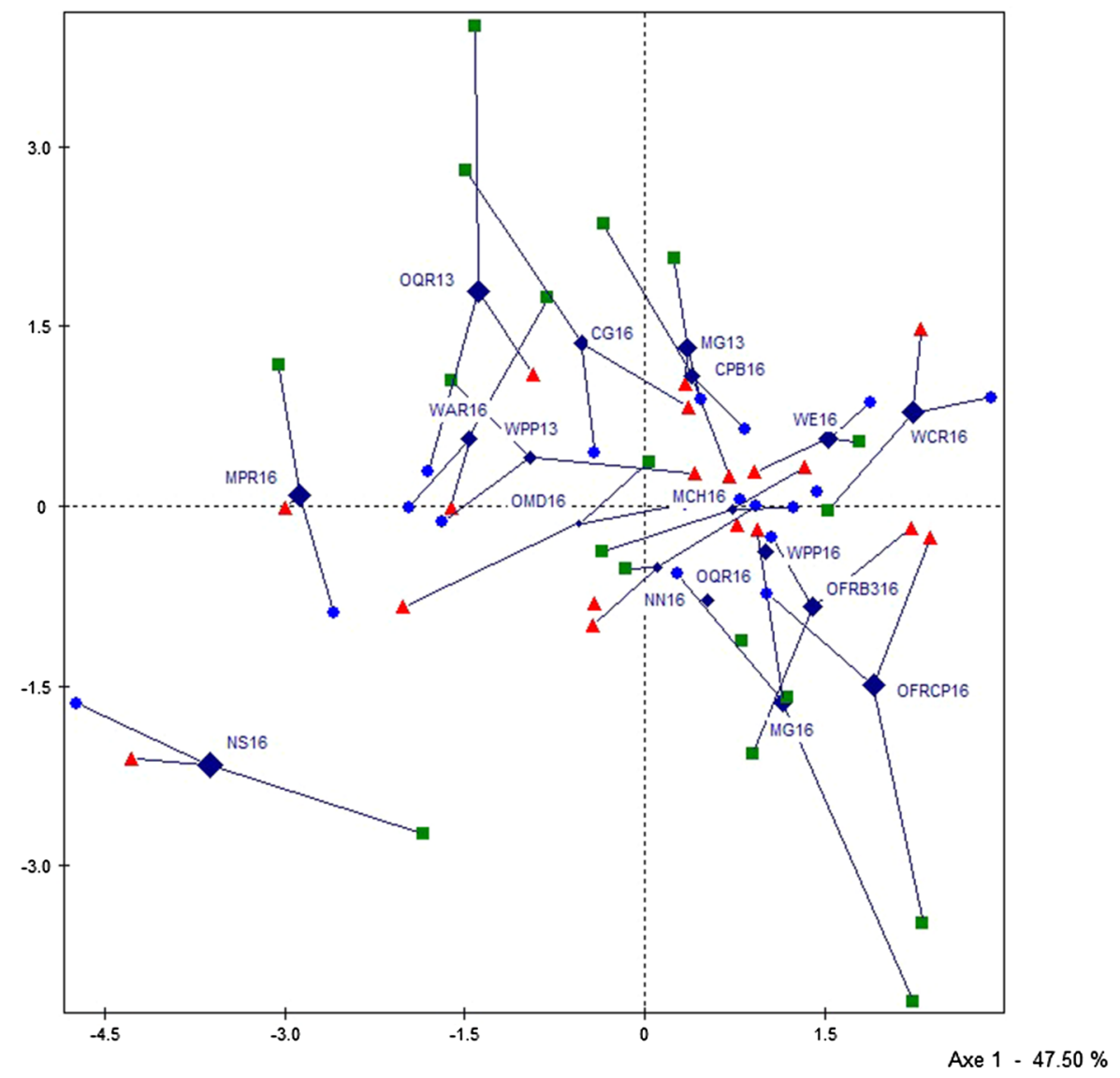

Fig. 2b. Representation of the wines on the first two dimensions of the MFA in the clear glass condition. The diamonds represent the average position of the wines. The size of the diamonds represents the quality of the representation of the wines (squared cosines) in the subspace. The triangles represent the position of the wines for the complexity attribute, the squares for the intensity attributes and the circles for the quality attributes.

\section{Discussion}

Given that various types of quality scores are awarded regularly by wine professionals at many wine-judging events (Parr et al., 2006; Dambergs, 2012), with results employed as marketing tools to influence consumer consumption and purchase behaviour, investigating scientifically what is quality in specific wine varieties is an overdue undertaking, not least for ethical reasons. The major aim of the present study was to investigate wine attributes driving wine professionals' perception of quality in the red wine Pinot noir with focus on related abstract concepts of complexity and varietal typicality. Our most important, overall outcome was demonstration that perceived wine quality, complexity, and varietal typicality are closely related concepts for wine professionals when assessing Pinot noir wines. We discuss our key findings below.

\subsection{Wine attributes driving quality judgments and complexity judgments}

In terms of the wine attributes assessed in this study, the most important drivers of quality in Pinot noir were descriptors varietal typicality, expressiveness, overall structure, and attractive fruit aromatics, along with complexity questionnaire attributes of harmony, balance and number of flavours. Reductive notes drove low-quality judgments. These results are consistent with structural aspects of the concept of perceived quality in Pinot noir wine reported by Valentin et al. (2016), strengthening that result given that the current study employed a larger wine sample set $(\mathrm{N}=18)$ and a wide range of wines in terms of $a$-priori judged quality (i.e., relative quality assumed by price). It is interesting that amongst the major drivers of overall quality were the major drivers of complexity, demonstrating a close relationship qualitatively between quality and complexity. These data allow a picture to emerge of the wine characteristics that wine professionals deem important in a Pinot noir wine judged to be of high quality, notably the concept of varietal typicality and the major drivers of overall complexity. In terms of perceived characters that render a wine low in quality, reductive notes and the green/herbaceous character stood out. Scientific evidence that the green characters, essential to perceived typicality in NZ's Sauvignon blanc wines (Parr et al., 2007), are not desirable in NZ's Pinot noir wines supports anecdotal evidence (e.g., comment from wine critics) and provides useful information for wine producers aiming to produce high-quality product.

The major drivers of perceived complexity shown in the present data are consistent with results reported by Schlich et al. (2015) and Meillon et al. (2010) in demonstrating harmony, balance and number of flavours perceived to be the major drivers of complexity as judged by wine professionals. They are as well to a large degree consistent with the results reported by Wang and Spence (2018) in their study with social drinkers. The current study therefore provides further support for the theoretical argument that perceived complexity in wine is a holistic notion, going beyond individual elements of a wine and their perceptual separability. Rather, as reported by Schlich et al. (2015) in their study involving wine professionals, connoisseurs and consumers tasting the white wine Sauvignon blanc, the most important attributes driving wine perceived complexity in the Pinot noir wines of the present study were integrating attributes of harmony and wine balance, along with the number of flavours. The attribute that could have favoured a perceptual separability hypothesis was the ease with which the individual flavours could be identified. This characteristic was not a significant driver of complexity in either the current data or those of Schlich et al. (2015) or Meillon et al. (2010). Finally, the present results, along with those reported by Wang and Spence (2018), provide evidence that the important drivers of perceived complexity are similar in red and white 


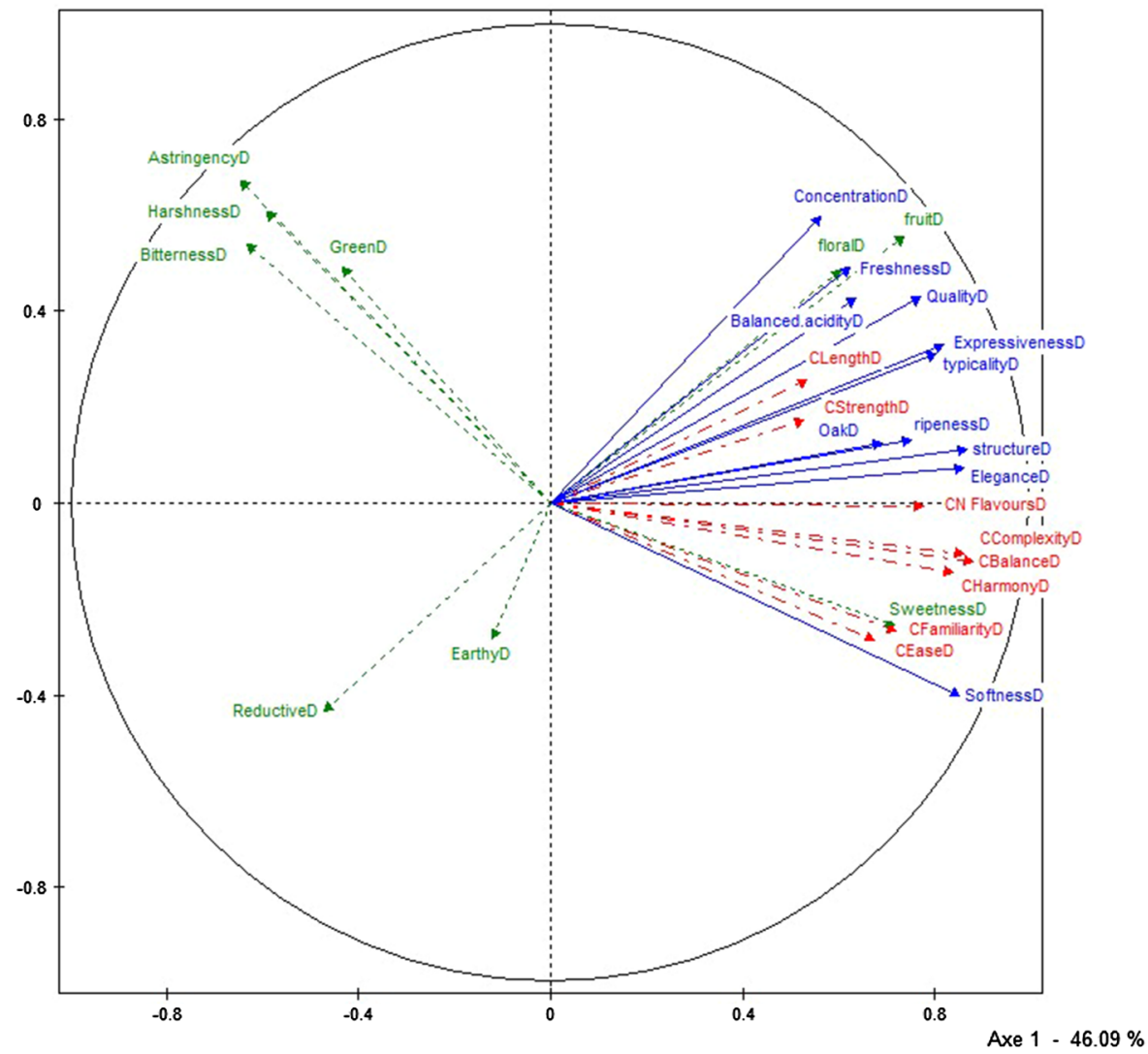

Fig. 3a. Representation of the attributes (dotted line = intensity; solid line = quality; dashed line = complexity) on the first two dimensions of the MFA in the black glass condition.

wine, namely global factors associated with a wine's perceived integration of its components (e.g., harmony).

Mouthfeel (trigeminal) attributes are important to appreciation of both white wine (Pickering and De Demiglio, 2008; Jones, Gawel, Francis, \& Waters, 2008) and red wine (Gawel, Oberholster, \& Francis, 2000; Laguna \& Sarkar, 2017; Saenz-Navajas et al., 2017). Hence, finding little significant influence of textural attributes on either perceived quality or perceived complexity in the present study was an unexpected result. Concentration-in-mouth, an attribute conceivably linked to the notion of wine body, was significantly associated with both quality and complexity. However, arguably the two most important in-mouth, sensory qualities in red wine for both consumers and wine professionals (De-la-Fuente-Blanco, Fernandez-Zurbano, Valentin, Ferreira, \& Saenz-Navajas, 2017; Gawel, 1998), namely the taste of bitterness and the sensation of astringency, both failed to show significant influence in the current study. Conceivably, this null result is due to high between-taster variability in perception of attributes such as bitterness (Bartoshuk, 2000) and astringency (Laguna \& Sarkar, 2017; Lesschaeve \& Noble, 2005) in the present study, rather than indicates that the attributes of astringency, tannin harshness, and so forth are not important to judgments of Pinot noir quality. We have followed this up in a subsequent study that is focusing solely on in-mouth attributes (tastes; trigeminal effects) of Pinot noir wines, the results of which will be reported in due course. Interestingly, a pilot data analysis involving only the three wines comprising two vintages $(2013 ; 2016)$, the analysis not reported in this article due to the small $N$, demonstrated that two of the three 2013 wines were judged significantly higher in astringency, harshness of tannins, green/herbaceous, and bitterness than the 2016 wine from the same producer.

\subsection{Relationship between quality and complexity judgments, and the importance of typicality}

Perceived quality and complexity were shown to be closely aligned concepts in Pinot noir wines for wine professionals. This is consistent with, and extends to wine professionals, the result of Wang and Spence (2018) who reported that for wine consumers, perceived complexity, quality and wine liking were positively correlated concepts. More specifically, all eight complexity-questionnaire characteristics positively correlated with overall quality in the present study, the higher correlations with quality being with harmony, balance, number of flavours, and familiarity. These results are largely in keeping with those reported by Schlich et al. (2015) and with Wang and Spence (2018), although the latter researchers failed to find an association between number of flavours and perceived complexity in their social drinkers' data. While reporting that many of the same wine attributes are subsumed within the concepts of quality and complexity, we also demonstrated some differences in how quality and complexity are conceptualised by wine professionals. In particular, varietal typicality was more closely aligned with perception of quality than with complexity.

Wine typicality is a cognitive construct (Parr et al., 2007; Sauvageot, 1994) involving a person's cerebral representation, i.e., a concept based on memories of prior experience with a particular wine variety. Varietal typicality is often extended to include wine origin, this known as regional or geographical typicality (Kustos et al., 2020; Parr et al., 2007). Our demonstration in the present study that perceived varietal typicality, wine quality, and complexity are closely related concepts for wine professionals, at least in NZ Pinot noir wines, is to our knowledge a novel result. It is however not an unexpected result, and supports anecdotal evidence and the sparse, relevant literature to date (e.g., Charters \& Pettigrew, 2007; Valentin et al., 2016). The very high 
Axe $2-1525 \%$

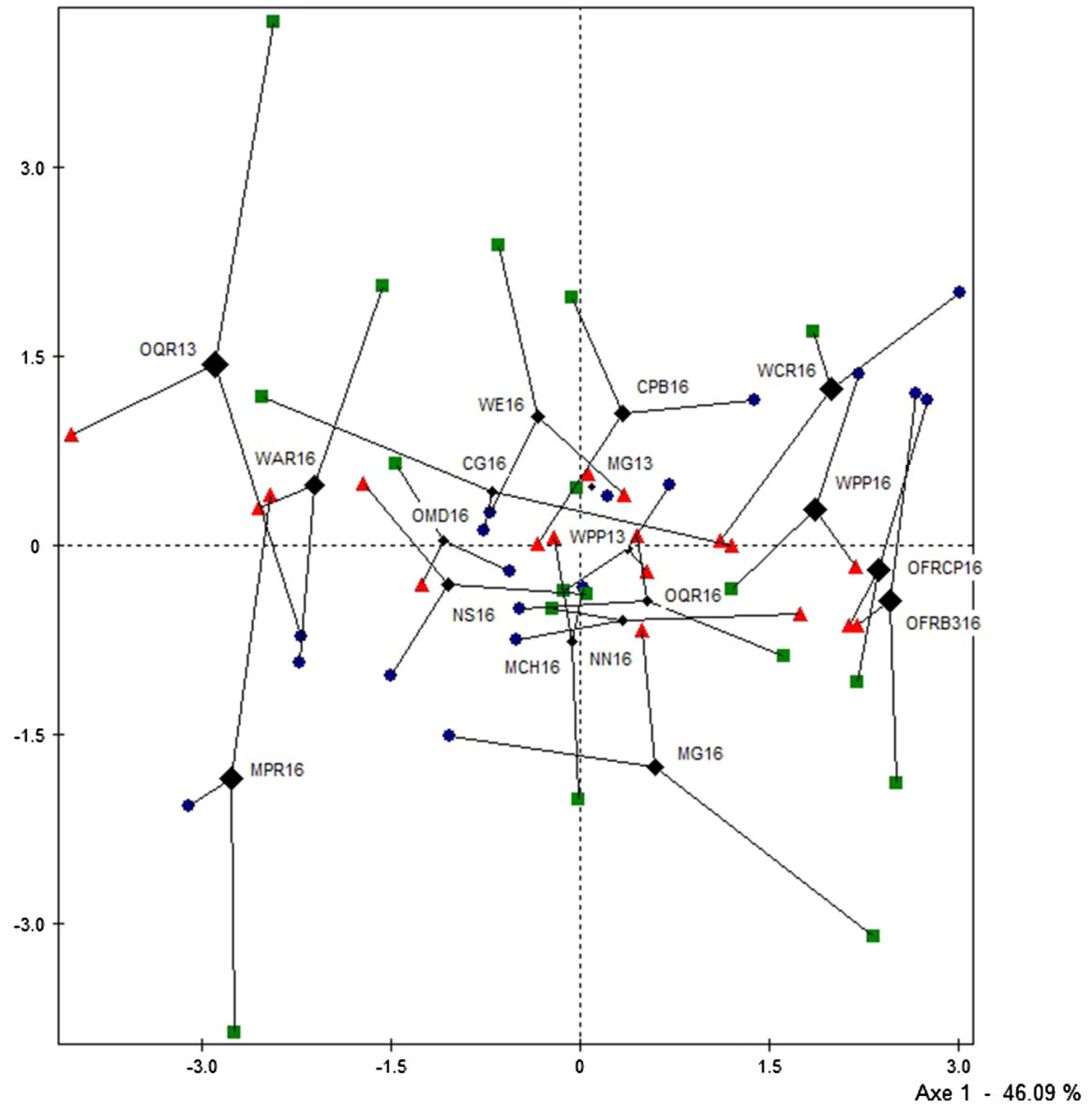

Fig. 3b. Representation of the wines on the first two dimensions of the MFA in the black glass condition. The diamonds represent the average position of the wines. The size of the diamonds represents the quality of the representation of the wines (squared cosines) in the subspace. The triangles represent the position of the wines for the complexity attribute, the squares for the intensity attributes and the circles for the quality attributes.
Table 5

Pearson Correlation coefficients between wine attributes and overall quality judgments in the clear and black glass conditions. Attributes statistically significant at $p<0.05$ are in bold.

\begin{tabular}{|c|c|c|c|c|}
\hline \multirow[b]{2}{*}{ Wine attributes } & \multicolumn{2}{|c|}{ Clear glass } & \multicolumn{2}{|c|}{ Black glass } \\
\hline & $\mathrm{r}$ & $\mathrm{R}^{2}$ & $\mathrm{r}$ & $\mathrm{R}^{2}$ \\
\hline Fruit ripeness & 0.91 & 0.83 & 0.65 & 0.42 \\
\hline Varietal typicality & 0.90 & 0.82 & 0.86 & 0.75 \\
\hline Expressiveness & 0.87 & 0.75 & 0.81 & 0.65 \\
\hline Overall structure & 0.86 & 0.74 & 0.85 & 0.72 \\
\hline Attractive fruit aromatics & 0.85 & 0.73 & 0.80 & 0.64 \\
\hline Oak influence & 0.82 & 0.67 & 0.65 & 0.42 \\
\hline Freshness & 0.79 & 0.62 & 0.70 & 0.49 \\
\hline Attractive floral aromatics & 0.78 & 0.61 & 0.57 & 0.32 \\
\hline Concentration in mouth & 0.74 & 0.55 & 0.73 & 0.54 \\
\hline Balanced acidity & 0.71 & 0.51 & 0.65 & 0.43 \\
\hline Sweetness & 0.64 & 0.40 & 0.31 & 0.10 \\
\hline Elegance precision & 0.63 & 0.40 & 0.73 & 0.53 \\
\hline Softness silkiness & 0.34 & 0.11 & 0.52 & 0.27 \\
\hline Astringency & 0.01 & 0.00 & -0.19 & 0.04 \\
\hline Earthy mushroom & -0.06 & 0.00 & 0.08 & 0.01 \\
\hline Harshness of tannins & -0.06 & 0.00 & -0.15 & 0.02 \\
\hline Bitterness & -0.10 & 0.01 & -0.18 & 0.03 \\
\hline Green herbaceous & -0.42 & 0.17 & -0.01 & 0.00 \\
\hline Reductive notes & -0.51 & 0.26 & -0.47 & 0.22 \\
\hline \multicolumn{5}{|l|}{ Complexity } \\
\hline Number of flavours & 0.74 & 0.55 & 0.61 & 0.37 \\
\hline Harmony & 0.72 & 0.51 & 0.65 & 0.42 \\
\hline Balance & 0.65 & 0.43 & 0.66 & 0.44 \\
\hline Familiarity & 0.58 & 0.34 & 0.53 & 0.28 \\
\hline Ease identify & 0.50 & 0.25 & 0.48 & 0.23 \\
\hline Length & 0.41 & 0.17 & 0.39 & 0.15 \\
\hline Strength of flavour & 0.38 & 0.14 & 0.44 & 0.19 \\
\hline
\end{tabular}

correlation between perceived quality and varietal typicality suggests that these two concepts are virtually synonymous concepts for NZ tasters judging NZ Pinot noir wines. It remains for future research to provide data as to whether such a result holds universally. In other words, to determine whether wine professionals in other important Pinot noir producing regions such as Burgundy, France, also consider

Table 6

Pearson Correlation coefficients between wine attributes and overall complexity judgments in the clear and black glass conditions. Attributes statistically significant at $p<0.05$ are in bold.

\begin{tabular}{|c|c|c|c|c|}
\hline \multirow[b]{2}{*}{ Wine attributes } & \multicolumn{2}{|c|}{ Clear glass } & \multicolumn{2}{|c|}{ Black glass } \\
\hline & $\mathrm{r}$ & $\mathrm{R}^{2}$ & $\mathrm{r}$ & $\mathrm{R}^{2}$ \\
\hline Overall structure & 0.78 & 0.60 & 0.78 & 0.61 \\
\hline Expressiveness & 0.72 & 0.52 & 0.70 & 0.49 \\
\hline Fruit ripeness & 0.78 & 0.60 & 0.60 & 0.36 \\
\hline Sweetness & 0.77 & 0.59 & 0.58 & 0.33 \\
\hline Varietal typicality & 0.71 & 0.51 & 0.61 & 0.37 \\
\hline Oak influence & 0.68 & 0.46 & 0.40 & 0.16 \\
\hline Elegance precision & 0.67 & 0.45 & 0.62 & 0.39 \\
\hline Concentration in mouth & 0.66 & 0.43 & 0.48 & 0.23 \\
\hline Attractive fruit aromatics & 0.63 & 0.40 & 0.44 & 0.19 \\
\hline Attractive floral aromatics & 0.61 & 0.37 & 0.37 & 0.14 \\
\hline Freshness & 0.54 & 0.29 & 0.47 & 0.22 \\
\hline Balanced acidity & 0.49 & 0.24 & 0.50 & 0.25 \\
\hline Softness silkiness & 0.34 & 0.11 & 0.74 & 0.54 \\
\hline Earthy mushroom & 0.08 & 0.01 & 0.01 & 0.00 \\
\hline Harshness of tannins & -0.17 & 0.03 & -0.46 & 0.21 \\
\hline Bitterness & -0.24 & 0.06 & -0.50 & 0.25 \\
\hline Astringency & -0.24 & 0.06 & -0.61 & 0.37 \\
\hline Green herbaceous & -0.29 & 0.08 & -0.35 & 0.12 \\
\hline Reductive notes & -0.35 & 0.12 & -0.32 & 0.10 \\
\hline
\end{tabular}


varietal typicality as virtually synonymous with perceived quality. In terms of perceived complexity, varietal typicality was positively associated with complexity, but to a lesser degree than with perceived quality.

\subsection{Influence of tasting-glass colour on Pinot noir chemosensory judgments}

In support of prior research (Valentin et al., 2016), ability to see a wine's colour was not the major driver of wine professionals' quality and complexity judgments in the current study. None-the-less, several interesting effects resulted from the glass-colour manipulation. First, when served in clear glassware, the Pinot noir wines were rated more positively on abstract attributes of overall quality, complexity, and varietal typicality. Further, the specific quality attributes rated more positively in the current study are strikingly similar to those judged more positively in clear glasses in Valentin et al.'s (2016) study involving French and NZ Pinot noir wines and French and NZ tasters. Hence, the current study replicates the positivity effect of the clear glass condition reported by Valentin et al., suggesting that this is not a spurious result but one worthy of serious consideration in further research, in particular given the frequent use of opaque glassware in current sensory research. Conceivable sources of visual influence include the following. First, contextual effects such as the black glass itself (e.g., the novel aspect of an opaque glass could serve an intimidating role, enhancing cautiousness or conservative responding in tasters). Second, perceptual effects could be involved where seeing colour and clarity of a wine induces cognitive and/or emotional positivity toward the product about to be tasted (Parr, 2019), influencing sensory judgments (e.g., via expectations).

Second, we demonstrated that being able to observe a wine's colour and clarity influenced wine professionals' judgments to wines at the ends of the price/quality spectrum. Interestingly, in their study of social drinkers' perceived complexity, Wang and Spence (2018) failed to find an influence of wine price on complexity. In the current study, whereas the majority of the wines were judged similarly across glass-colour conditions, the lowest-price wine (wine NS16), which was also judged lowest in overall quality, was judged even more negatively when its visual characteristics of low density and high hue (browning) were accessible to tasters (e.g., judged lower in strength of flavour when in the clear glass). Conversely, the most expensive wine in the sample set, wine WRC16, a wine judged high in terms of overall quality and shown instrumentally to have high colour density and low hue measures, was judged significantly higher on strength of flavour when in the clear glass than when its visual characteristics were occluded. These effects suggest that wine colour contributes minimally to wine professionals' sensory responses to Pinot noir wines unless a wine is at either the very high or very low end of the price and quality spectrums. To our knowledge this is a novel result, with clear implications for wine producers and wine marketing professionals.

\subsection{Conclusion}

This study has been successful in extending prior work on wine quality by including co-investigation of perceived complexity in red wine, and by providing evidence that particular chemosensory attributes subsumed within the umbrella concept of varietal typicality are important drivers of both perceived quality and complexity. By employing a behavioural (tasting) study and wine professionals as tasters, we have substantiated the previously suggested link between perceived quality and perceived complexity reported by Charters and Pettigrew (2007) and demonstrated in social drinkers by Wang and Spence (2018). Further, we have demonstrated that despite the two higherorder, abstract concepts of quality and complexity having many attributes in common, there were some interesting differences, notably in their association to the important, fine wine attribute of varietal typicality. Finally, we have provided evidence that a wine's colour density and hue (browning) may be used by wine professionals as a cue, influencing smell, taste and mouthfeel phenomena, when judging wines at the ends of the perceived quality spectrum. In terms of future directions, a study in progress is following up our null result regarding inmouth attributes (taste of bitter; trigeminal effects), focusing solely on in-mouth attributes important to Pinot noir perceived quality. Finally, in terms of implications, our research is significant in that we have added empirical data and theoretical argument that can contribute to understanding human perception of abstract concepts such as quality and complexity in complex food and beverage stimuli.

\section{Declaration of Competing Interest}

The authors declare that they have no known competing financial interests or personal relationships that could have appeared to influence the work reported in this paper.

\section{Acknowledgement}

The project was funded by New Zealand's Bragato Research Institute, New Zealand Winegrowers, and the New Zealand Ministry of Business, Innovation, and Employment (MBIE). We thank Damian Martin, Linlin Leymann, and Marian Vlaar for assistance with wine selection, data collection, and data entry, respectively, and the 22 wine professionals who served as participants.

\section{Appendix A. Supplementary material}

Supplementary data to this article can be found online at https:// doi.org/10.1016/j.foodres.2020.109423.

\section{References}

ASTM (1986). Physical requirement guidelines for sensory evaluation laboratories. Philadelphia: ASTM STP 913. ASTM Publications.

Auvray, M., \& Spence, C. (2008). The multisensory perception of flavour. Consciousness and Cognition, 17, 1016-1031.

Ballester, J., Dacremont, C., Le Fur, Y., \& Etievant, P. (2005). The role of olfaction in the elaboration and use of the Chardonnay wine concept. Food Quality and Preference, 16, 351-359.

Bartoshuk, L. M. (2000). Comparing sensory experiences across individuals: Recent psychophysical advances illuminate genetic variation in taste perception. Chemical Senses, 25, 447-460.

Campo, E., Ballester, J., Langlois, J., Dacremont, C., \& Valentin, D. (2010). Comparison of conventional descriptive analysis and a citation frequency-based descriptive method for odor profiling: An application to Burgundy Pinot noir wines. Food Quality and Preference, 21, 44-55.

Casassa, L. F., Sari, S. E., Bolcato, E. A., Diaz-Sambueza, M. A., Catania, A. A., Fanzone, M. L., ... Barda, N. (2019). Chemical and sensory effects of cold soak, whole cluster fermentation, and stem additions in Pinot noir wines. American Journal of Enology and Viticulture, 70, 19-33.

Charters, S., \& Pettigrew, S. (2007). The dimensions of wine quality. Food Quality and Preference, 18, 997-1007.

Cliff, M. A., \& Dever, M. C. (1996). Sensory and compositional profiles of British Columbia Chardonnay and Pinot noir wines. Food Research International, 29, $317-323$.

Dambergs, R. G. (2012). Manipulating Pinot noir red wine quality in the winery. Proceedings of the 8th international cool climate symposium, 31 January-4 February, 2012, Hobart, Tasmania, Australiahttp://winetasmania.com.au/resources/downloads.

De Beer, D., Harbertson, J. F., Kilmartin, P. A., Roginsky, V., Barsukova, T., Adams, D. O., \& Waterhouse, A. L. (2004). Phenolics: A comparison of diverse analytic methods. American Journal of Enology \& Viticulture, 55, 389-400.

De-la-Fuente-Blanco, A., Fernandez-Zurbano, P., Valentin, D., Ferreira, V., \& SaenzNavajas, M.-P. (2017). Cross-modal interactions and effects of the level of expertise on the perception of bitterness and astringency of red wines. Food Quality and Preference, 62, 155-161.

Frost, S. C., Harbertson, J. F., \& Heymann, H. (2017). A full factorial study on the effect of tannins, acidity, and ethanol on the temporal perception of taste and mouthfeel in red wine. Food Quality and Preference, 62, 1-7.

Gawel, R. (1998). Red wine astringency: A review. Australian Journal of Grape and Wine Research, 4, 74-95.

Gawel, R., Oberholster, A., \& Francis, I. L. (2000). A mouth-feel wheel: Terminology for communicating the mouth-feel characteristics in red wine. Australian Journal of Grape and Wine Research, 6, 203-207.

Hopfer, H., \& Heymann, H. (2014). Judging wine quality: Do we need experts, consumers 
or trained panelists? Food Quality and Preference, 32, 221-233.

Jones, P. R., Gawel, R., Francis, I. L., \& Waters, E. J. (2008). The influence of interactions between major white wine components on the aroma, flavour and texture of model white wine. Food Quality and Preference, 19, 596-607.

Kemp, S. E., \& Gilbert, A. N. (1997). Odor intensity and color lightness are correlated sensory dimensions. American Journal of Psychology, 110, 335-351.

Kramer, M. (2012). How to really taste wine. Wine Spectator, December 18th. http:// www.winespectator.com/webfeature/show/id/47792 (last accessed 13/5/20).

Kustos, M., Gambetta, J. M., Jeffery, D. W., Heymann, H., Goodman, S., \& Bastian, S. E. P. (2020). A matter of place: Sensory and chemical characterization of fine Australian Chardonnay and Shiraz wines of provenance. Food Research International, 130, 108903. https://doi.org/10.1016/j.foodres.2019.108903.

Laguna, L., \& Sarkar, A. (2017). Oral tribology: Update on the relevance to study as tringency in wines. Tribology - Materials, Surfaces \& Interfaces, 11, 116-123.

Lattey, K. A., Bramley, B. R., \& Francis, I. L. (2010). Consumer acceptability, sensory properties and expert quality judgements of Australian Cabernet Sauvignon and Shiraz wines. Australian Journal of Grape and Wine Research, 16, 189-202.

Lesschaeve, I., \& Noble, A. C. (2005). Polyphenols: Factors influencing their sensory properties and their effects on food and beverage preferences. American Journal of Clinical Nutrition, 81, 330S-335S.

Medel Maraboli, M. (2011). Perception de la qualité du vin par les consommateurs. [Perception of wine quality by consumers]. Ph.D. thesis defended on November 4th, 2011 at the University of Burgundy, Dijon, France. Available online at: http://nuxeo. u-bourgogne.fr/nuxeo/site/esupversions/db53998b-0c6b-450a-a1ea-2a40da557a11.

Meillon, S., Viala, D., Medel, M., Urbano, C., Guillot, G., \& Schlich, P. (2010). Impact of partial alcohol reduction in Syrah wine on perceived complexity and temporality of sensations and link with preference. Food Quality and Preference, 21, 732-740.

Melcher, J., \& Schooler, J. (1996). The misremembrance of wines past: Verbal and perceptual expertise differentially mediated verbal overshadowing of taste memory. Journal of Memory and Language, 35, 231-245.

Mercurio, M., Dambergs, R. G., Cozzolino, D., Herderich, M. J., \& Smith, P. A. (2010). Relationship between red wine grades and phenolics. 1. Tannin and total phenolic concentrations. Journal of Agricultural and Food Chemistry, 58, 12313-12319.

Morrot, G., Brochet, F., \& Dubourdieu, D. (2001). The color of odors. Brain and Language, 79, 309-320.

Pangborn, R. M., Berg, H. W., \& Hansen, B. (1963). The influence of color on discrimination of sweetness in dry table wine. American Journal of Psychology, 76, 492-495.

Parr, W. V. (2019). Demystifying wine tasting: Cognitive psychology's contribution. Food Research International, 124, 230-233.

Parr, W. V., Ballester, J., Peyron, D., Grose, C., \& Valentin, D. (2015). Investigation of perceived minerality in Sauvignon wines: Influence of culture and mode of perception. Food Quality and Preference, 41, 121-132.

Parr, W. V., Green, J. A., \& White, K. G. (2006). Wine judging, context, and New Zealand Sauvignon Blanc. European Review of Applied Psychology, 56, 231-238.

Parr, W. V., Green, J. A., White, K. G., \& Sherlock, R. R. (2007). The distinctive flavour of New Zealand Sauvignon Blanc: Sensory characterisation by wine professionals. Food Quality and Preference, 18, 849-861.

Parr, W. V., Heatherbell, D. A., \& White, K. G. (2002). Demystifying wine expertise: Olfactory threshold, perceptual skill, and semantic memory in expert and novice wine judges. Chemical Senses, 27, 747-755.

Parr, W. V., Mouret, M., Blackmore, S., Pelquest-Hunt, T., \& Urdapilleta, I. (2011). Representation of complexity in wine: Influence of expertise. Food Quality and Preference, 22, 647-660.

Parr, W. V., Valentin, D., Green, J. A., \& Dacremont, C. (2010). Evaluation of French and New Zealand Sauvignon wines by experienced French wine assessors. Food Quality and Preference, 21, 56-64

Parr, W. V., White, K. G., \& Heatherbell, D. A. (2003). The nose knows: Influence of colour on perception of wine aroma. Journal of Wine Research, 14, 79-101.

Parr, W. V. (2015). Unraveling the nature of perceived complexity in wine. Practical Winery \& Vineyard, 5-8.

Pickering, G., \& Demiglio, P. (2008). The white wine mouthfeel wheel: A lexicon for describing the oral sensations elicited by white wine. Journal of Wine Research, 19, 51-67.

Rankin, B. C., \& Pocock, K. F. (1970). Alkalimetric determination of sulphur dioxide in wine. Australian Wine, Brewing \& Spirit Review, 88, 40-44.

Robinson, J. (2019). When terroir trumps quality. Jancisrobinson.com, May 29, 2018.

Rodrigues, H., Saenz-Navajas, M.-P., Franco-Luesma, E., Valentin, D., Fernando-Zurbano, P., Ferreira, V., ... Ballester, J. (2017). Sensory and chemical drivers of wine minerality aroma: An application to Chablis wines. Food Chemistry, 230, 553-562.

Saenz-Navajas, M.-P., Avizcuri, J.-M., Ballester, J., Fernandez-Zurbano, P., Ferreira, V., Peyron, D., \& Valentin, D. (2015). Sensory-active compounds influencing wine experts' and consumers' perception of red wine intrinsic quality. LWT - Food Science and Technology, 60, 400-411.

Saenz-Navajas, M. P., Avizcuri, J. M., Echávarri, J. F., Ferreira, V., Fernández-Zurbano, P., \& Valentin, D. (2016). Understanding quality judgements of red wines by experts: Effect of evaluation condition. Food Quality and Preference, 16, 216-227.

Saenz-Navajas, M.-P., Avizcuri, J.-M., Ferrero-del-Teso, S., Valentin, D., Ferreira, V., \& Frenandez-Zurbano, P. (2017). Chemo-sensory characterization of fractions driving different mouthfeel properties in red wines. Food Research International, 94, 54-64.

Sauvageot, F. (1994). Les sciences de l'aliment et le concept de typicité ou le chercheur en sciences de la nature a-t-il quelque chose a déclarer sur la typicité d'un produit alimentaire? Sciences des Aliments, 14, 557-571.

Schlich, P., Medel, M., Urbano, C., \& Parr, W. V. (2015). Perceived complexity in Sauvignon blanc wine: Influence of domain-specific expertise. Australian Journal of Grape \& Wine Research, 21(2), 168-178. https://doi.org/10.1111/ajgw.12129.

Singleton, V. L., \& Ough, C. S. (1962). Complexity of flavour and blending of wines. Journal of Food Science, 27, 189-196.

Somers, C. T., \& Evans, M. E. (1977). Spectral evaluation of young red wines: Anthocyanin equilibria, total phenolics, free and molecular SO2, "chemical age" Journal of the Science of Food and Agriculture, 28, 279-287.

Spence, C., Levitan, C. A., Shankar, M. U., \& Zampini, M. (2010). Does food color influence taste and flavor perception in humans? Chemosensory Perception, 3, 68-84.

Spence, C., \& Wang, Q. J. (2018). On the meaning(s) of perceived complexity in the chemical senses. Chemical Senses, 43, 451-461.

Stillman, J. A. (1993). Color influences flavor identification in fruit-flavored beverages. Journal of Food Science, 58, 810-812.

Thorngate, J. H. (1997). The physiology of human sensory response to wine. American Journal of Enology \& Viticulture, 48, 271-279.

Tomasino, E., Harrison, R., Sedcole, R., \& Frost, A. (2013). Regional differentiation of New Zealand Pinot noir wine by wine professionals using canonical variate analysis. American Journal of Enology and Viticulture, 64, 357-363.

Valentin, D., Parr, W. V., Peyron, D., Grose, C., \& Ballester, J. (2016). Colour as a driver of Pinot noir wine quality judgments: An investigation involving French and New Zealand wine professionals. Food Quality and Preference, 48, 251-261.

Wang, Q. J., \& Spence, C. (2018). Wine complexity: An empirical investigation. Food Quality and Preference, 68, 238-244.

Zellner, D. A. (2013). Color-odor interactions: A review and model. Chemosensory Perception, 6, 155-169.

Zellner, D., \& Whitten, L. A. (1999). The effect of color intensity and appropriateness on color-induced odor enhancement. American Journal of Psychology, 112, 585-604. 